\title{
Removal of Potassium from Molasses by Solvent Extraction and Ion Exchange
}

\author{
Lingyun Wang, Sang-Ho Nam, ${ }^{\dagger}$ and Manseung Lee ${ }^{*}$ \\ Department of Advanced Material Science \& Engineering, Institute of Rare Metal, Mokpo National University, \\ Channam 534-729, Korea. ${ }^{*}$-mail: mslee@mokpo.ac.kr \\ 'Department of Chemistry, Mokpo National University, Chonnam 534-729, Korea \\ Received March 28, 2014, Accepted May 14, 2014
}

\begin{abstract}
The high content of potassium in molasses limits its usage as a raw material for stock feed. Moreover, its high viscosity makes it difficult to develop an efficient removal process. In this study, ion exchange and solvent extraction experiments have been performed to investigate the removal of potassium from a mixture of molasses with water. Cationic exchange resins (AG50W-X8 and Diphonix) showed a high loading percentage of potassium but the occurrence of breakthrough in few bed volumes was a drawback to the industrial application. Among the cationic extractants (D2EHPA, PC 88A, Cyanex 272) tested in this study, saponified PC $88 \mathrm{~A}$ was found to be the best extractant for the removal of potassium. Batch simulation studies on a three stage counter current extraction confirmed that $85 \%$ of potassium was removed from $50 \mathrm{wt} \%$ molasses solution in water by using saponifed PC 88A.
\end{abstract}

Key Words : Molasses, Potassium, Ion exchange, Solvent extraction, PC 88A

\section{Introduction}

The term molasses refers to the final effluent resulted from the manufacture of sugar by repeated evaporation, crystallization and centrifugation of juices from sugar cane and sugar beets. It is residual syrup from which sucrose can be obtained. ${ }^{1}$ World production of molasses has been extensively increased to 64.0 million ton per year due to its widespread usage as a raw material for the production of alcohol, amino acids, yeast, fertilizer and animal feed. ${ }^{2}$ The composition of molasses depends on the quality of sources and on the processing technology. It is reported that a high level of organic content, such as crude proteins, amino acid, glycerol, cholesterol is contained in molasses and approximately $50 \%$ sugar exists in the form of sucrose and invert sugar. $^{3}$

Molasses has palatability with nutrient value and its physical properties could be utilized to reduce the dustiness of feed and thus to help the manufacture of pellets. ${ }^{4}$ Molasses can become a raw material for animal feeds. The use of molasses as the feed for livestock and poultry dates back to nineteenth century. ${ }^{4-6}$ However, the fact that high potassium content in molasses could incur bulls and pigs diarrhea limits the dosage of molasses. ${ }^{7-10}$ On the other hand, molasses is also used as a raw material for potassium fertilizer. For this reason, removal of potassium from molasses has become an important task. ${ }^{11}$

Unit operations such as chemical precipitation, electrodialysis, reverse osmosis, nano membrane and ion exchange have been investigated to remove potassium from molasses due to the fact that potassium exists as an ionic form in molasses. ${ }^{812-17} \mathrm{~A}$ literature survey on the removal of potassium from molasses reveals that solvent extraction has never been tried to remove potassium from molasses.
The objective of our study is to develop a process for the reduction of potassium content in molasses by employing solvent extraction and ion exchange. Since solvent extraction and ion exchange is a process which needs phase contact, mass transfer of a solute from one phase to the other phase is very important. However, molasses is very viscous and mass transfer coefficient of a solute in molasses is too small for equilibrium to be attained. Therefore, synthetic solution containing potassium was first employed in the ion exchange and solvent extraction experiments to investigate the loading or extraction behavior of potassium. For this purpose, cation exchange resin (Diphonix and AG50W-X8) and cationic extractants (D2EHPA, PC 88A, Cyanex 272) and their saponified forms were employed. Batch simulation studies on the counter current extraction of potassium from the mixture of molasses with water verified that the content of potassium in molasses could be reduced to $15 \%$ by using saponified PC 88A.

\section{Experimental}

Materials. AG50W-X8 (Eichrom, USA) and Diphonix (Eichrom, USA) are strong cationic exchange resins with hydrogen form. In the experiments, AG50W-X8 and Diphonix resins were used as received without any treatment. Bi-2-ethylhexylphosphoric acid (D2EHPA), bis(2,4,4-trimethylpentyl) phosphinic acid (Cyanex 272), and 2-ethylhexylphosphonic acid mono-2-ethylhexyl ester (PC 88A) were purchased from Cytec Canada Inc. These extractants were used as such without any further purification. Escaid 110 (Exxon) was used as a diluent in solvent extraction experiments.

Saponified extractant $(10,30,50 \%$ neutralized) was prepared by adding a stoichiometric amount of concentrated 
$\mathrm{NaOH}$ solution and $2 \%(\mathrm{v} / \mathrm{v})$ TBP was added as a modifier. ${ }^{18}$ The mixture was stirred until a single phase was formed and then the resulting solution was washed with deionized water several times.

Synthetic solution of potassium was prepared by dissolving the necessary amount of potassium chloride $(99.0 \%$, Showa Chemical Co.) in deionized water. Throughout the whole experiments, the concentration of potassium in synthetic solution was kept at $200 \mathrm{ppm}$. The initial $\mathrm{pH}$ value of the synthetic solution was adjusted with $\mathrm{HCl} / \mathrm{NaOH}$ solution and all the other chemicals used were of analytical grade.

The molasses-water mixture solution was prepared by diluting the molasses with necessary amount of deionized water. Then, it was mechanically stirred thoroughly by a magnetic stirrer for $1 \mathrm{~h}$ so that a homogeneous mixture was obtained.

Viscosity Measurement Procedure. A Cannon-Fenske routine viscometer (Cannon Instrument Company) which consists of a U-shaped glass tube held vertically in a $25^{\circ} \mathrm{C}$ water bath was employed to measure the viscosity of samples by measuring the efflux time. The liquid is drawn slightly to the capillary tube by suction using pump (FMI lab pump, QG20). The liquid was allowed to flow freely through the capillary tube between two etched mark and the time of liquid flow was measured using a stopwatch. Deionized water was first tried as a reference liquid, and then each molasses-water mixture samples. Each efflux time was checked by running the liquid through the capillary tube for 8 times.

Solvent Extraction and Ion Exchange Procedure. In solvent extraction experiments, equal volume $(20 \mathrm{~mL})$ of aqueous and organic phase was mixed in a $100 \mathrm{~mL}$ screwed cap bottle and shaken for 30 min with a wrist action shaker. The aqueous phase was separated after settling the mixture. All the extraction experiments were carried out at ambient temperature.

Ion exchange batch experiments were carried out in a shaking incubator (HB-201SF, Hanbaek Scientific Co.) using $100 \mathrm{~mL}$ screwed cap bottle. The temperature of the shaking incubator was controlled to $25^{\circ} \mathrm{C} .50 \mathrm{~mL}$ of solutions were bottle rolled for $24 \mathrm{~h}$ after putting certain amount of resin. The loaded resin was separated by filtration.

In continuous experiments, a glass column $(250 \times 10 \mathrm{~mm})$ was used, where certain amount of resin was poured. The operation was performed at a constant flow rate of $1.5 \mathrm{~mL} /$ min. Flow rate of the solution was controlled using pump (FMI lab pump, QG20). The effluent was fractionated into portions of one bed volume and the concentration of metal in each fraction was measured. The change in the metal concentration of the effluent was represented using concentration fraction which was defined as

$$
\text { Concentration fraction }=\frac{\text { concentration of metal in the effluent }}{\text { concentration of metal in the feed }}
$$

The concentration of potassium in the aqueous phase was measured by ICP-OES (Perkin-Elmer Inc., Optima 4300 DV model). The concentration of potassium in the organic or the resin was calculated according to mass balance.

\section{Results and Discussion}

Viscosity of Molasses. Mass transfer coefficient is related to the viscosity of a solution. Since molasses is very viscous, high input energy is needed to stir the molasses. Therefore, reduction of the viscosity of molasses is prerequisite in developing a process to remove potassium from molasses by employing ion exchange and solvent extraction. Except increasing the temperature of molasses, one of the methods to reduce the viscosity of molasses is to add water to molasses. For this purpose, viscosity values of molasses-water mixtures in which the weight percentage of water was varied from zero (pure molasses) to 50\% were measured.

Figure 1 shows the variation in the viscosity and density of the mixture of molasses and water with the wt \% of water. Density and the logarithm of viscosity of molasses-water mixtures decreased steadily with the increase of $\mathrm{wt} \%$ of water in the mixture. The value of viscosity decreased from $1837 \mathrm{cp}$ for pure molasses to $1 \mathrm{cp}$ for $50 \mathrm{wt} \%$ mixture. The density of pure molasses was $1.37 \mathrm{~g} / \mathrm{mL}$, while that of the 50 wt \% mixture was $1.15 \mathrm{~g} / \mathrm{mL}$. In this study, the molasseswater mixture with $50 \mathrm{wt} \%$ of water was selected in the solvent extraction and ion exchange experiments.

\section{Removal of Potassium by Ion Exchange.}

Ion Exchange of Potassium from the Synthetic Solution: Batch ion exchange experiments with Diphonix and AG50W-X8 resin were performed to investigate the loading behavior of potassium from synthetic solution. Throughout the experiments, the concentration of potassium was kept at $200 \mathrm{ppm}$ in the synthetic solution, while the initial $\mathrm{pH}$ was kept at $6 .{ }^{19}$ Effect of resin concentration on the loading of potassium is shown in Figure 2. The concentration of Diphonix resin was varied from 0.5 to $10 \mathrm{~g} / \mathrm{L}$, while that of AG50W-X8 resin was varied from 2 to $20 \mathrm{~g} / \mathrm{L}$. Both Diphonix and AG50W-X8 resin was found to have adsorption ability for potassium. The loading percentage of potassium increased slightly with increasing resin concentration. The highest loading percentage of potassium was $75 \%$ at $10 \mathrm{~g} / \mathrm{L}$ Diphonix resin and $82 \%$ at $20 \mathrm{~g} / \mathrm{L}$ AG50W-X8 resin, respec-

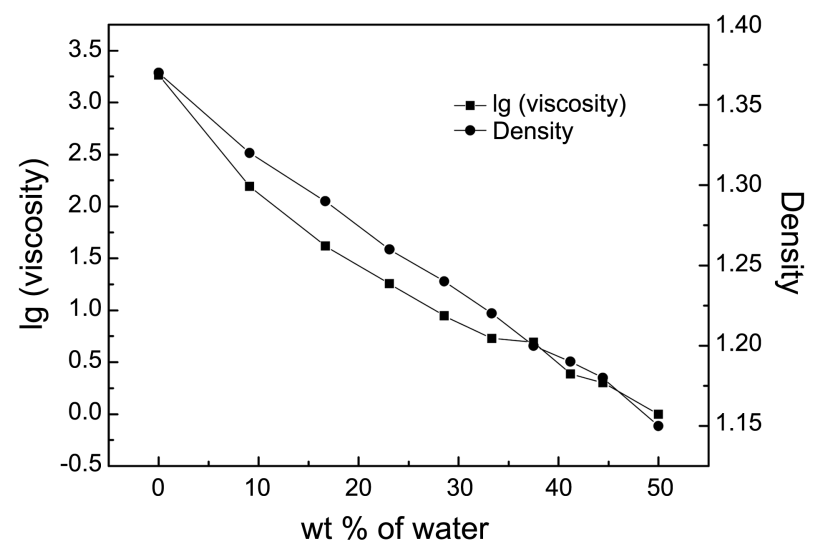

Figure 1. Effect of wt \% of water in molasses on the $\lg$ (viscosity) and density at $25^{\circ} \mathrm{C}$. 

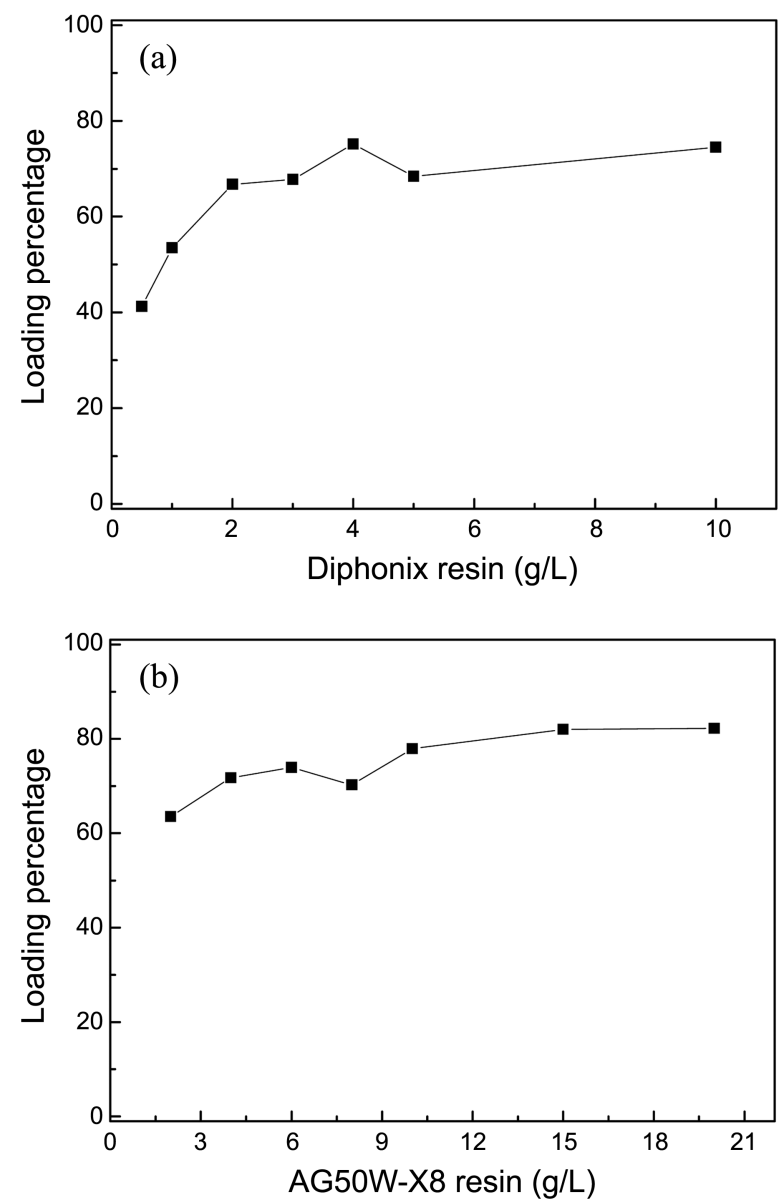

Figure 2. Effect of resin concentration on the adsorption of $\mathrm{K}$ from synthetic solution.

tively.

Ion Exchange of Potassium from Molasses Mixture. Batch experiments indicate that it is possible to remove potassium from the synthetic solution with Diphonix and AG50W-X8 resin. The viscosity of molasses makes it difficult to filter the resin after batch ion exchange experiments. Therefore, $50 \mathrm{wt} \%$ molasses-water mixture was used in continuous experiments to test the possibility of removing potassium from the mixture by these two resins. The concentration of potassium in $50 \mathrm{wt} \%$ molasses-water mixture was $16.43 \mathrm{~g} / \mathrm{L}$. In these continuous experiments, glass column was employed and the amount of Diphonix and AG50W-X8 resin was fixed at $20 \mathrm{~g}$ and $10 \mathrm{~g}$, respectively.

Figure 3 shows the continuous experimental results with 50 wt \% molasses-water mixture. By using Diphonix resin, $93 \%$ of potassium was loaded at the first bed volume ( 1 bed volume was $33 \mathrm{~mL}$ ). However, after the first bed volume the loading of potassium decreased sharply with the increase of bed volume. Breakthrough occurred in the third bed volume. Similarly, more than $85 \%$ of potassium was loaded with AG50W-X8 resin at the first and second bed volume ( 1 bed volume was $10 \mathrm{~mL}$ ). Thereafter, most of the potassium appeared in the effluent. This phenomenon may be due to the high concentration of potassium $(16.43 \mathrm{~g} / \mathrm{L})$ in $50 \mathrm{wt} \%$ molasses-water mixture employed in the experiments. Figure

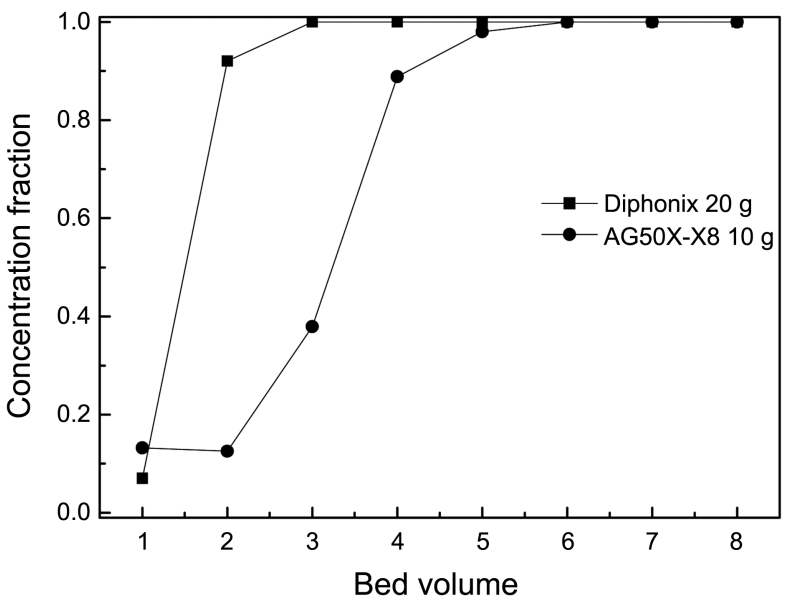

Figure 3. Variation in the concentration fraction of $\mathrm{K}$ with bed volume in the effluent during continuous experiments from 50 wt $\%$ molasses-water mixture.

3 indicates that it is possible to remove potassium from 50 wt \% molasses-water mixture. However, considering the occurrence of the breakthrough in a few bed volumes, it is difficult to employ ion exchange on industrial scale to remove potassium from molasses.

Removal of Potassium by Solvent Extraction.

Solvent Extraction of Potassium from the Synthetic Slution: In the solvent extraction of metal ions by cationic extractants, it has been reported that the extraction percentage of the metal ions becomes a maximum in the vicinity of solution $\mathrm{pH}$ where metal ions begin to precipitate. According to the Eh-pH diagram of potassium at $25^{\circ} \mathrm{C}$, potassium ion is stable in the $\mathrm{pH}$ range from zero to $14 .^{20}$ Therefore, synthetic solution with initial $\mathrm{pH}$ of 6 was employed in the solvent extraction experiments.

In order to investigate the effect of the nature and concentration of extractants on the extraction of potassium from the synthetic solution, cationic extractants, such as D2EHPA, PC 88A and Cyanex 272 were employed and the concentration was varied from 0.1 to $1 \mathrm{M}$. As shown in Table 1 , the extraction percentage of potassium with these three extractants was low and increased slightly with increasing extractant concentration in our experimental range. The highest extraction percentage of $23 \%$ was obtained by 1 M PC $88 \mathrm{~A}$. The equilibrium $\mathrm{pH}$ of the synthetic solution decreased after the solvent extraction, indicating that cation exchange mech-

Table 1. Effect of the extractant concentration on the extraction of $\mathrm{K}$ and equilibrium $\mathrm{pH}$ from synthetic solution

\begin{tabular}{ccccccccc}
\hline \multirow{2}{*}{$\begin{array}{c}\text { Conc. } \\
\text { (M) }\end{array}$} & \multicolumn{2}{c}{ D2EHPA } & & \multicolumn{2}{c}{ PC 88A } & & \multicolumn{2}{c}{ Cyanex 272 } \\
\cline { 2 - 3 } \cline { 7 - 8 } \cline { 8 - 9 } & EX \% & Eq-pH & & EX \% & Eq-pH & & EX \% & Eq-pH \\
\hline 0.1 & 6.5 & 3.41 & & 16.2 & 3.05 & & 9 & 3.30 \\
0.3 & 11 & 2.69 & & 15.8 & 3.03 & & 13.6 & 2.91 \\
0.5 & 18.7 & 2.56 & & 19.1 & 2.61 & & 13.7 & 2.87 \\
0.7 & 18 & 2.57 & & 21.9 & 2.48 & & 12.4 & 2.76 \\
1 & 16.44 & 2.62 & & 22.6 & 2.53 & & 12.1 & 2.75 \\
\hline
\end{tabular}


anism is responsible for the solvent extraction of potassium by the extractants tested in this study. The liberation of hydrogen ion led to lower extraction of potassium owing to the decrease in solution $\mathrm{pH}$ of the aqueous phase.

This problem can be overcome by saponifying cationic extractants with $\mathrm{NaOH}$. In the case of solvent extraction with a saponified extractant, sodium ions are first replaced by cationic metal ions in preference to hydrogen ions. ${ }^{21}$ Thus, the acidity of the aqueous solution remains under control and the extraction efficiency of potassium could be enhanced. Therefore, the effect of the saponification degree of extractants was investigated on the extraction of potassium from synthetic solution.

The concentration of D2EHPA, PC 88A and Cyanex 272 was kept at $0.1 \mathrm{M}$, while the saponification degree of each extractant was varied from zero to $50 \%$. Figure 4 shows that the extraction percentage of potassium increased with increasing saponification degree. Compared to D2EHPA and Cyanex 272, saponified PC 88A shows a good extractability of potassium and an extraction percentage of $51 \%$ was observed by $50 \%$ saponified $0.1 \mathrm{M} \mathrm{PC} 88 \mathrm{~A}$.

In the following experiments, the effect of PC 88A concentration at various saponification degree on the extraction of potassium was investigated from synthetic solution and the results are shown in Figure 5. The extraction efficiency of potassium increased with increasing PC 88A concentration as well as saponification degree. In the case of PC 88A without saponification, the extraction percentage of potassium increased from 16 to $22 \%$ with increasing PC $88 \mathrm{~A}$ concentration, while with $50 \%$ saponified PC $88 \mathrm{~A}$ the highest extraction percentage of $71 \%$ was obtained at the concentration of $0.7 \mathrm{M}$. It can be concluded that among the cationic extractants tested in this study, extraction with $50 \%$ saponified 0.7 M PC 88A was found to be an optimum condition to remove potassium from the synthetic solution.

Solvent Extraction of Potassium from the Molasses Mixture: As observed in the solvent extraction of synthetic solution by using different extractants, the saponified PC $88 \mathrm{~A}$ was chosen to be an adequate extractant to remove

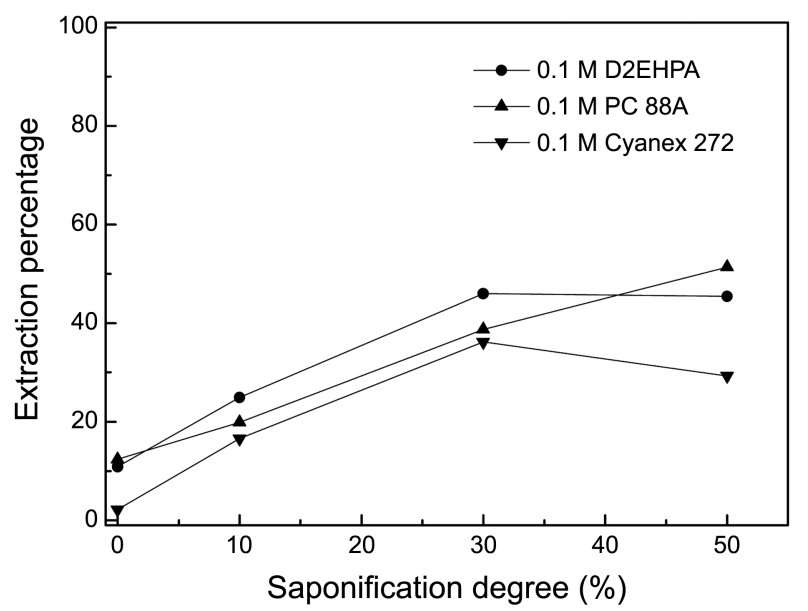

Figure 4. Effect of the saponification degree on the extraction of $\mathrm{K}$ from synthetic solution.

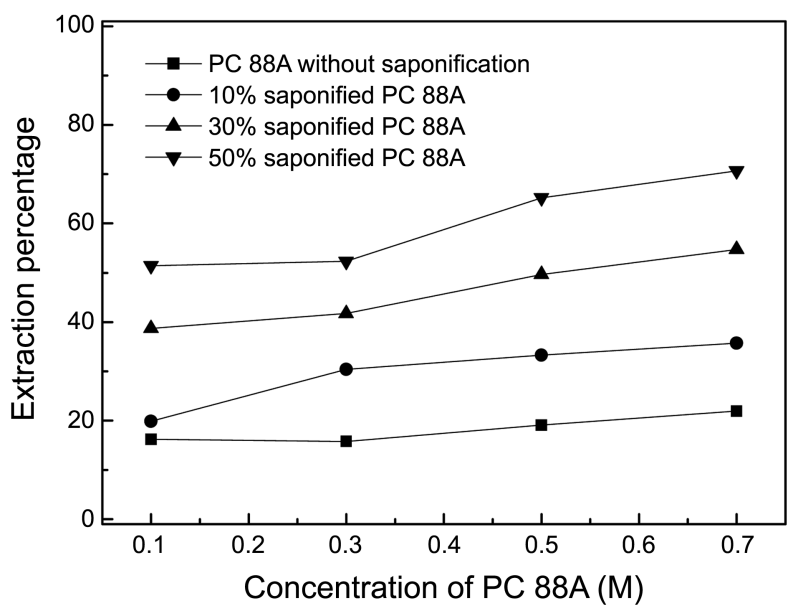

Figure 5. Effect of the PC $88 \mathrm{~A}$ concentration on the extraction of $\mathrm{K}$ using different saponification degree from synthetic solution.

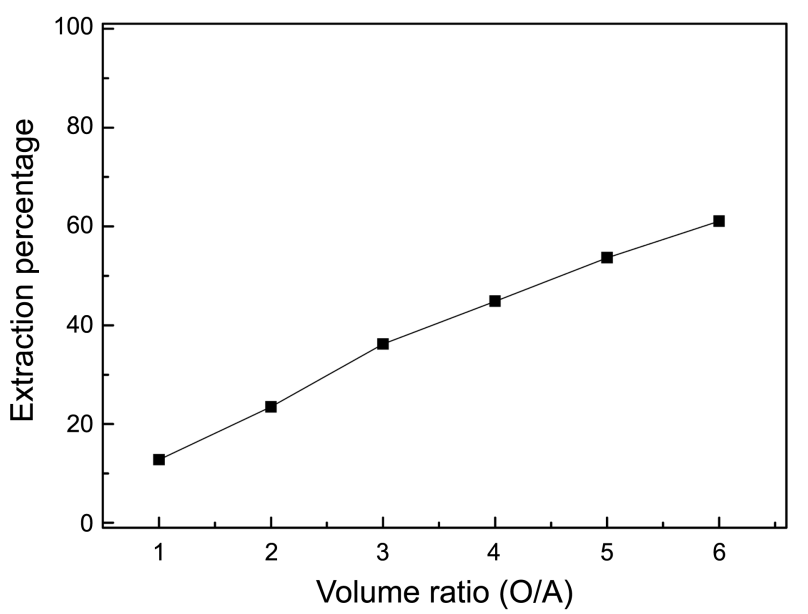

Figure 6. Effect of the organic to aqueous volume ratio on the extraction of K by $50 \%$ saponified $0.7 \mathrm{M}$ PC $88 \mathrm{~A}$ from $50 \mathrm{wt} \%$ molasses-water mixture.

potassium. Therefore, $50 \%$ saponified $0.7 \mathrm{M} \mathrm{PC} \mathrm{88A} \mathrm{was}$ used in the solvent extraction of potassium from $50 \mathrm{wt} \%$ molasses mixture. The results shown in Figure 6 indicate that the extraction percentage of potassium from the mixture was only $13 \%$ when the volume ratio of organic to aqueous was unity. This might be explained by the high concentration of potassium in $50 \mathrm{wt} \%$ molasses mixtures and the limitation of extraction capacity of saponified PC 88A. With the increase of the volume ratio of organic to aqueous $(\mathrm{O} / \mathrm{A}$ ratio), the extraction percentage increased steadily and the extraction of potassium reached $61 \%$ at an O/A ratio of 6 .

In multiple extraction by using mixer-settler, the concentration ratio of a solute after $n$ extraction stage is given by ${ }^{22}$

$$
\frac{C_{n}}{C_{i n i}}=\left(\frac{1}{1+D \frac{V_{o r g}}{V_{a q}}}\right)^{n}
$$

where $C_{n}$ and $C_{i n i}$ represent the concentration of a solute after $\mathrm{n}$ extraction and in feed, respectively. $D$ is a distribution 
coefficient and $V_{a q}$ and $V_{\text {org }}$ represent the volume of aqueous and organic phase, respectively.

In Figure 6, the extraction percentage of potassium by $50 \%$ saponified $0.7 \mathrm{M}$ PC $88 \mathrm{~A}$ was $13 \%$, which corresponds to distribution coefficient of 0.13 . When the volume ratio of organic to aqueous is 6, Eq. (2) indicates that at least 3 extraction stages are needed to remove $85 \%$ potassium from the $50 \mathrm{wt} \%$ molasses mixture. Therefore, batch simulation experiments on a three stage counter-current extraction were carried out at an O/A ratio of 6 using 50\% saponified $0.7 \mathrm{M}$ PC 88A, and the results are displayed in Figure 7 . The concentration of potassium in the $50 \mathrm{wt} \%$ molasses-water mixture was $16.43 \mathrm{~g} / \mathrm{L}$ of potassium, while the concentration of potassium in raffinate was $2.48 \mathrm{~g} / \mathrm{L}$. These results clearly suggest that $85 \%$ of the potassium in the $50 \mathrm{wt} \%$ mixture could be removed after 3 stage counter current extraction with $50 \%$ saponified 0.7 M PC 88A.

Stripping of Potassium from Loaded Saponified PC 88A: Stripping of potassium from the loaded saponified PC $88 \mathrm{~A}$ is necessary to regenerate the extractant. Concentrated $\mathrm{HCl}$ solutions were tested by varying the concentration from 1 to $9 \mathrm{M}$ at unit phase ratio. For this purpose, the loaded organic was prepared by extraction of potassium from the 50 wt $\%$ molasses-water mixture with $50 \%$ saponified $0.7 \mathrm{M}$ $\mathrm{PC} 88 \mathrm{~A}$ at an $\mathrm{O} / \mathrm{A}$ ratio of 6 . The obtained results in Figure 8 show that quantitative stripping of potassium was achieved with the studied concentration rage of 1 to $9 \mathrm{M} \mathrm{HCl}$. Hence $1 \mathrm{M} \mathrm{HCl}$ was selected as a strip solution to strip potassium from the loaded saponified PC 88A. Stripping isotherm was

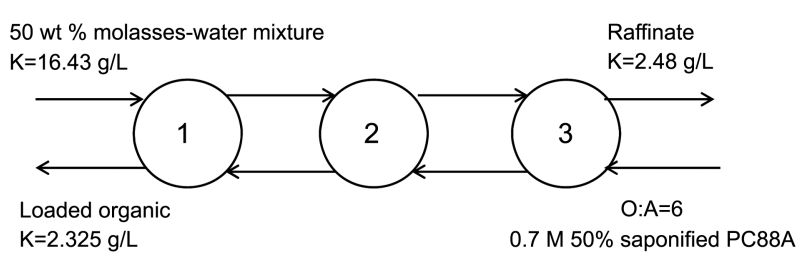

Figure 7. Three stage counter current extraction simulation studies for $\mathrm{K}$ extration from $50 \mathrm{wt} \%$ molasses-water mixture by $0.7 \mathrm{M}$ $50 \%$ saponified $\mathrm{PC} 88 \mathrm{~A}$ at $\mathrm{O} / \mathrm{A}$ ratio of 6 .

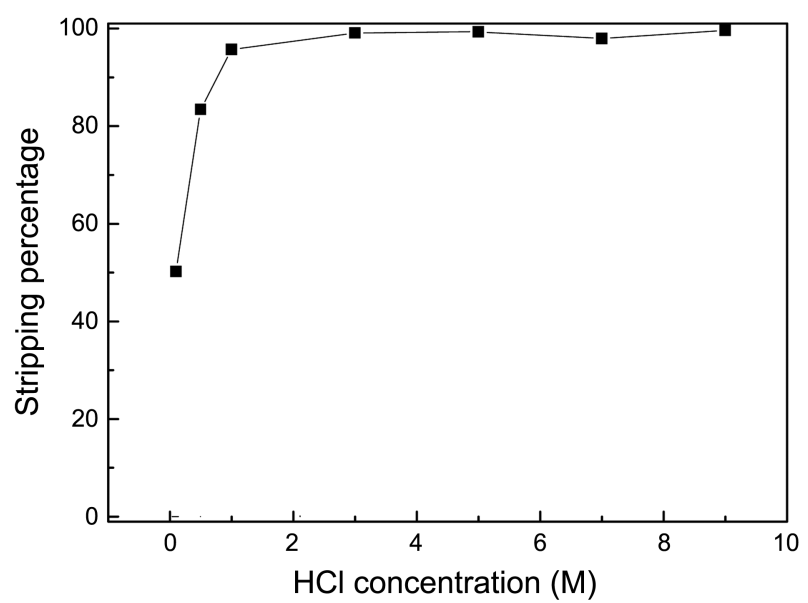

Figure 8. Effect of $\mathrm{HCl}$ concentration on the $\mathrm{K}$ stripping, Loaded organic was obtained by extract $\mathrm{K}$ from $50 \mathrm{wt} \%$ molasses-water mixture with 0.7 M 50\% saponified PC 88A at O/A ratio of 6 .

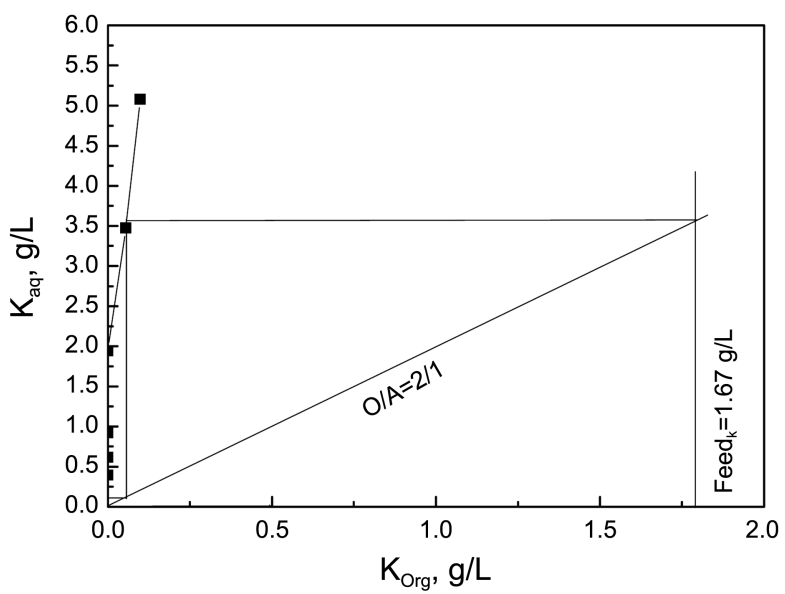

Figure 9. McCabe-Thiele plot for K stripping, Strip solution = $1 \mathrm{M}$ $\mathrm{HCl}, \mathrm{K}$ in loaded organic phase $=1.67 / \mathrm{L}$, Loaded organic was obtained by extract $\mathrm{K}$ from $50 \mathrm{wt} \%$ molasses-water mixture with $0.7 \mathrm{M} 50 \%$ saponified PC $88 \mathrm{~A}$ at $\mathrm{O} / \mathrm{A}$ ratio of 6 .

constructed to predict the number of stages and flow rates of the two phases for the maximum stripping of potassium. McCabe-Thiele plot (Figure 9) illustrated that two stages are needed for complete stripping of potassium from the loaded saponified $\mathrm{PC} 88 \mathrm{~A}$ at an $\mathrm{O} / \mathrm{A}$ ratio of 2.

Finally, our present work indicates that $85 \%$ of potassium in molasses can be successfully removed by the solvent extraction with saponified PC 88A. Since these results were obtained from the $50 \mathrm{wt} \%$ molasses mixture, more experiments should be done on the use of this mixture for a raw material of molasses.

\section{Conclusions}

Ion exchange and solvent extraction experiments have been done to investigate the removal of potassium from molasses. Batch ion exchange experiments indicated that potassium was loaded into cationic ion exchange resins (Diphonix and AG50W-X8). Continuous ion exchange experiments with these resins revealed that more than $80 \%$ of potassium could be removed from $50 \mathrm{wt} \%$ molasses mixture. However, the occurrence of the breakthrough in a few bed volumes was a drawback in its application on industrial scale. In solvent extraction, saponified PC 88A was found to be adequate to extract potassium among the tested extractants (D2EHPA and Cyanex 272). Batch simulation studies on a three stage counter-current extraction confirmed that $85 \%$ of potassium could be removed from $50 \mathrm{wt} \%$ molasses mixture by $50 \%$ saponified $0.7 \mathrm{M}$ PC $88 \mathrm{~A}$. Loaded potassium in saponified PC $88 \mathrm{~A}$ could be completely stripped by $1 \mathrm{M}$ $\mathrm{HCl}$.

Acknowledgments. This work was supported by Basic Science Research Program through the National Research Foundation of Korea (NRF) funded by the Ministry of Education, Science and Technology (grant Number: 2011-0023778). We gratefully thank the Gwangju branch of the Korea Basic Science (KBSI) for ICPAES data. 


\section{References}

1. Paturau, J. M. Byproducts of the Cane Sugar Industry: An Introduction to Their Industrial Utilization, 3rd ed.; Elsevier Science Ltd Press: Amsterdam, Oxford, New York, Tokyo, 1989; p 435.

2. F. O. Licht News; World: 2012/13 Molasses production 3\% up on year; http://www.toepfer.com/news/archive/2013/july/article/world201213-molasses-production-3-up-on-year/; 2013.

3. Zayed, G. J. Ind. Microbiol. Biot. 1997, 19, 39.

4. Cleasby, T. G. Proc. S. Afr. Sug. Technol. Ass. 1963, 47, 113.

5. Scott, M. L. Use of Molasses in the Feeding of Farm Animals: Review and Annotated Bibliography; Sugar Res Foundation Press: New York, 1953.

6. Waldroup, P. W. World Poultry Sci. J. 1981, 37, 193.

7. Fernandez, B.; Bodas, R.; Lopez-Campos, O.; Andres, S.; Mantecon, A. R.; Giraldez, F. J. J. Anim. Sci. 2009, 87, 2055.

8. Decloux, M.; Bories, A.; Lewandowski, R. et al. Desalination 2002, 146, 393.

9. Stemme, K.; Gerdes, B.; Harms, A.; Kamphues, J. J. Anim. Physiol. Anim. Nutr. 2005, 89, 179.

10. Yalcin, S.; Eltan, O.; Karsli, M. A.; Yalcin, S. Rev. Med. Vet. 2010, $161,245$.
11. Wynne, A. T.; Meyer, J. H. Proc. S. Afr. Sug. Technol. Ass. 2002, $76,71$.

12. Xu, K.; Wang, C.; Liu, H.; Qian, Y. Chemosphere 2011, 84, 207.

13. Acevedo-Morantes, M.; Colon, G.; Realpe, A. Desalination 2011, 278, 354.

14. Richards, L. A.; Richards, B. S.; Schaefer, A. I. J. Membr. Sci. 2011, 369, 188.

15. Lucas, A. D.; Can̆izares, P.; Rodríguez, J. F.; Gracia, I. Chem. Eng. J. 1997, 66, 137.

16. Zhang, P. J.; Zhao, Z. G.; Yu, S. J.; Guan, Y. G.; Li, D.; He, X. Desalination 2012, 286, 210.

17. Kim, H. H.; Chang, Y. K. J. Membr. Sci. 2009, 342, 173.

18. Sarangi, K.; Reddy, B. R.; Das, R. P.; Manchanda, V. K. Hydrometallurgy 1999, 52, 253.

19. Abubaker, H. O.; Sulieman, A. M. E.; Elamin, H. B. J. Microbiol. Res. 2012, 2, 36.

20. Takeno, N. Atlas of Eh-pH Diagrams; Geological Survey of Japan Open File Report No. 419; 2005; p 128.

21. Lee, M. S.; Lee, J. Y.; Kim, J. S.; Lee, G. S. Sep. Purif. Technol. $\mathbf{2 0 0 5}, 46,72$.

22. Habashi, F. Textbook of Hydrometallurgy, 2nd ed.; Metallurgie Extractive Quebec Press: Quebec City, Canada, 1999; p 445. 